\title{
Componentes morfológicos e produção de forragem de pastagem de aveia e azevém manejada em diferentes alturas
}

\author{
Angelo Antonio Queirolo Aguinaga ${ }^{1}$, Paulo César de Faccio Carvalho ${ }^{2}$, Ibanor Anghinoni ${ }^{3}$, \\ Alcides Pilau ${ }^{4}$, Antonio José Queirolo Aguinaga ${ }^{4}$, Gustavo Dal Forno Gianluppi ${ }^{5}$ \\ 1 PPG - Zootecnia/UFRGS. Bolsista CAPES. \\ 2 Departamento de Plantas Forrageiras e Agrometeorologia, UFRGS, Av. Bento Gonçalves 7712, CEP: 91501-970, Porto Alegre, RS, Brasil. \\ ${ }^{3}$ Departamento de Solos, UFRGS. \\ ${ }^{4}$ PPG - Zootecnia/UFRGS. \\ ${ }^{5}$ Curso de Graduação em Agronomia/UFRGS.
}

RESUMO - Avaliou-se a dinâmica de produção de forragem em pastagem de aveia-preta (Avena strigosa Schreb) e azevém (Lolium multiflorum Lam) manejada em diversas alturas de manejo com o objetivo de evidenciar as potencialidades dessa mistura em sistemas de integração lavoura-pecuária. Os tratamentos consistiram de quatro alturas de manejo da pastagem (10; 20; 30 e $40 \mathrm{~cm}$ ), medidas com bastão graduado e avaliadas em blocos casualizados com três repetições. O método de pastejo foi contínuo, com taxa de lotação variável. Utilizaram-se bezerros de corte mestiços com 10 meses de idade e peso médio inicial de $210 \mathrm{~kg}$, respectivamente. As características da pastagem estudadas foram: massa de forragem (MF); taxa de acúmulo de forragem (TAC); produção total de forragem (PTMS); e quantificação dos componentes morfológicos da pastagem (colmo, lâmina e material morto). A massa de forragem aumentou de forma linear de acordo com a altura do pasto, uma vez que, para cada $\mathrm{cm}$ de aumento na altura superior a $10 \mathrm{~cm}$, a matéria seca aumentou aproximadamente $90 \mathrm{~kg} / \mathrm{ha}$. Não houve efeito das alturas da pastagem sobre a TAC ou sobre a PTMS, cujos valores médios foram de 66,8 $\mathrm{kg} / \mathrm{ha} / \mathrm{dia}$ de MS e $10.721 \mathrm{~kg} / \mathrm{ha}$ de MS, respectivamente. A porcentagem de folhas de azevém foi maior que a de folhas de aveia nos três períodos de avaliação e, na altura de $10 \mathrm{~cm}$, foi superior à obtida nas demais alturas na última avaliação (em torno de $20 \%$ da participação total da massa de forragem). A aveia apresenta rápido desenvolvimento inicial e diminuição na produção nos períodos posteriores de desenvolvimento.

Palavras-chave: altura do pasto, Avena strigosa, componentes morfológicos, Lolium multiflorum, massa de forragem, taxa de acúmulo

\section{Morphological components and forage production of oat (Avena strigosa, Schreb) and annual ryegrass (Lolium multiflorum, Lam) pasture managed at different heights}

\begin{abstract}
Forage growth dynamic in an Oat (Avena strigosa, Schreb) + Ryegrass (Lolium multiflorum, Lam) pasture managed at different grazing heights was evaluated in order to access the mixed-sward potential in a crop-livestock integrated system. Treatments were four sward grazing heights $(10,20,30$, and $40 \mathrm{~cm})$, measured with a sward-stick. The experimental design was a random block with three replications. The grazing method utilized was continuous stocking with variable stocking rate. Beef steers weighting $210 \mathrm{~kg}$ with approximately 10 month old were used. The analyzed variables were herbage mass (HM), herbage growth rate (GR), dry matter production (DMP), and the morphological components (stem, leaf and senescent material). A linear increase was observed for herbage mass as herbage height increased. Results showed that for every centimeter in sward height above $10 \mathrm{~cm}$ means approximately $90 \mathrm{~kg}$ DM/ha. Treatments did not affect the GR and the DMP, and the average values were $66.8 \mathrm{~kg} \mathrm{DM} / \mathrm{ha} /$ day and 10,721 kg DM/ha, respectively. Ryegrass leaf presented greater proportion than oat leaf in the three evaluation periods, showing higher values for the treatment $10 \mathrm{~cm}$ in the last evaluation (about $20 \%$ of participation in the total biomass). Oat presented a fast initial development and decreased the production on the later periods.
\end{abstract}

Key Words: Avena strigosa, growth rate, herbage mass, Lolium multiflorum, structure components, sward height

Este artigo foi recebido em 30/7/2005 e aprovado em 1/4/2008.

Correspondências devem ser enviadas para angeloa@sebrae-rs.com.br. 


\section{Introdução}

O cenário produtivo tem provocado mudanças de objetivos entre produtores, que têm apresentado constante desejo de utilização de sistemas mais produtivos, muitas vezes substituindo pastagens naturais por pastagens plantadas ou por culturas agrícolas.

No Rio Grande do Sul (RS), o campo nativo é a principal fonte de forragem na bovinocultura de corte. O campo nativo é formado basicamente por espécies estivais, com elevada produção de forragem no período primavera-verão e baixas taxas de crescimento, com redução na qualidade no período outono-inverno. Para suprir a deficiência outono-hibernal, é possível utilizar pastagens plantadas de estação fria, como aveia-preta (Avena strigosa, Schreb) e azevém (Lolium multiflorum, Lam), que apresentam alto valor nutritivo e elevado potencial produtivo. Restle et al. (2000) obtiveram 641 e $865 \mathrm{~kg} /$ ha de peso vivo, respectivamente com 150 e $300 \mathrm{~kg} / \mathrm{ha}$ de nitrogênio em mistura de aveia preta e azevém, o que comprova o alto potencial produtivo destas espécies.

Considerando a relevância das pastagens hibernais no contexto agropecuário do Sul do Brasil, é necessário quantificar e avaliar suas características produtivas e a sustentabilidade de seu uso ao longo do tempo, o que é válido tanto em regiões especializadas apenas em pecuária como em áreas de integração lavoura-pecuária. Pastagens integradas a lavouras de grãos contribuem conservando e melhorando o solo e atenuando problemas como a ocorrência de pragas, doenças e plantas daninhas.

O sucesso do sistema de integração lavoura-pecuária depende de diversos fatores, que são dinâmicos e interagem entre si. Entre os componentes do sistema, destacam-se o solo, a planta e o animal. O animal, por meio da desfolhação, pode afetar o nível de palhada residual, que é a base para implantação da lavoura de verão no sistema de semeadura direta.

Pensando em sustentabilidade da integração do gado e das lavouras de grãos, é importante definir a lotação animal que permite melhor combinação de produtividades, não necessariamente as maiores, entre forragem no inverno e grãos no verão (Machado, 2002). Assim, em sistemas integrados, é provável que não exista um nível único de palhada residual que promova, ao mesmo tempo, elevados ganhos individuais e por área dos animais e altos rendimentos de grãos da cultura de verão (Cassol, 2003). As alturas de manejo determinam a quantidade total de matéria seca (MS) produzida (aérea e radicular), a magnitude do impacto do pisoteio animal e a quantidade de MS reciclada no sistema.
Pastos submetidos a diversas intensidades de pastejo podem ter efeitos na dinâmica de participação das espécies e de seus componentes morfológicos e definir a altura ótima de condução do pasto para o sistema como um todo, evidenciando as potencialidades de misturas de espécies forrageiras em um sistema de integração lavoura-pecuária. Objetivou-se neste trabalho avaliar a dinâmica da produção de forragem em uma pastagem de aveia e azevém manejada em diferentes alturas de manejo.

\section{Material e Métodos}

O experimento foi conduzido na Fazenda Espinilho, pertencente à Agropecuária Cerro Coroado e localizada no município de São Miguel das Missões, região fisiográfica do Planalto Médio do Rio Grande do Sul.

Os dados de precipitação foram obtidos com a ajuda de pluviômetro de campo (Tabela 1).

A área experimental (21,5 ha) é utilizada desde 1995 no sistema de semeadura direta, sempre com cultivo de soja no verão. No inverno, até o ano 2000, utilizou-se a cultura de aveia como cobertura e, a partir daí, a área passou a ser trabalhada em sistema de integração lavoura-pecuária, com semeadura anual de uma mistura de aveia e azevém.

O solo é classificado como Latossolo Vermelho Distroférrico típico, desenvolvido a partir de rochas eruptivas básicas, profundo, bem drenado, com coloração vermelhoescura e textura muito argilosa ( $>60 \%$ de argila) (Embrapa, 1999), com relevo suavemente ondulado.

Os tratamentos consistiram de quatro alturas de manejo do pasto $(10,20,30$ e $40 \mathrm{~cm})$ mais uma área sem pastejo (SP), com altura variável conforme o livre crescimento e a senescência do pasto. Utilizaram-se 65 bezerros de corte de cruzamento industrial entre as raças Angus, Hereford, Charolês e Nelore, com idade e peso médio inicial de 10 meses e $210 \mathrm{~kg}$, respectivamente. O pastejo foi realizado pelo método contínuo com taxa de lotação variável, composto de animais-teste e reguladores. Os animais reguladores entravam ou saíam da pastagem conforme a necessidade de

Tabela 1 - Precipitação registrada $(\mathrm{mm})$ na área experimental durante os meses de avaliação

\begin{tabular}{lc}
\hline Mês & Precipitação $(\mathrm{mm})$ \\
\hline Abril & 279 \\
Maio & 40 \\
Junho & 129 \\
Julho & 191 \\
Agosto & 85 \\
Setembro & 75 \\
Outubro & 363 \\
Novembro & 245 \\
\hline
\end{tabular}


ajuste da altura da pastagem, por meio da técnica de taxa de lotação variável (put-and-take), descrita por Mott \& Lucas (1952).

O experimento teve início no dia 19/5/2003 com a implantação das espécies de inverno, no sistema de semeadura direta, pela semeadura de aveia-preta $(100 \mathrm{~kg} / \mathrm{ha}) \mathrm{e}$ azevém ( $25 \mathrm{~kg} / \mathrm{ha}$ ). A adubação foi realizada na ocasião da semeadura, por meio da aplicação de superfosfato simples (400 kg/ha), e no dia 4/7/2003, com aplicação de nitrogênio (N) em cobertura $(90 \mathrm{~kg} / \mathrm{ha})$ na forma de uréia. Os animais foram inseridos nas unidades experimentais no dia $21 / 7 / 2003$, quando a pastagem atingiu $25 \mathrm{~cm}$ de altura e massa de forragem de $2.000 \mathrm{~kg} / \mathrm{ha}$ de MS, e mantidos até $7 / 11 / 2003$, quando foram retirados e abatidos, logo, o período de pastejo totalizou 109 dias.

A altura do pasto foi estimada utilizando-se um bastão graduado, cujo marcador corre por uma régua desde o topo da superfície da pastagem, constituída de lâminas verdes, até a superfície do solo (Barthram, 1985). As avaliações foram feitas em intervalos de 15 dias, totalizando sete avaliações no período de pastejo, e os pontos de avaliação foram definidos de forma aleatória, totalizando 100 pontos por unidade experimental, com o objetivo de definir a altura média da pastagem.

A massa de forragem foi avaliada a cada 30 dias, com quatro cortes aleatórios por unidade experimental em um quadrado de $0,25 \mathrm{~m}^{2}$ e 100 pontos de medição de altura com o bastão graduado. O corte foi feito com tesoura elétrica no nível do solo e acima do mantilho. As amostras cortadas foram colocadas em saco de papel, secas em estufa de circulação forçada a $65^{\circ} \mathrm{C}$ durante quatro dias e, posteriormente, foram pesadas. O valor médio das medições da altura de planta em cada piquete foi utilizado como variável independente em equações de regressão que relacionaram as medições de altura com o valor de massa de forragem real obtido nos cortes.

A taxa de acúmulo de MS foi monitorada a cada 30 dias utilizando-se três gaiolas de exclusão de pastejo por unidade experimental e empregando a técnica do triplo emparelhamento (Euclides et al., 1992). As quantidades de MS dentro e fora da gaiola foram obtidas por corte com tesoura, com corte rente ao solo, em área delimitada por um quadro de $0,25 \mathrm{~m}^{2}$. As amostras cortadas eram colocadas em saco de papel, secas em estufa de ventilação forçada a $65^{\circ} \mathrm{C}$ durante quatro dias e posteriormente pesadas.

A produção total de MS foi calculada pelo somatório da massa de forragem inicial com as produções de cada período, obtidas multiplicando-se a taxa de acúmulo diário pelo número de dias do período. No mesmo material coletado para determinação da massa de forragem, procedeu-se à quantificação dos componentes morfológicos do pasto pela separação manual de lâmina foliar e colmos de aveia e de azevém, além do material morto de ambas as espécies. Depois de separado, o material foi colocado em sacos de papel, identificados e mantidos em estufa de ventilação forçada a $65^{\circ} \mathrm{C}$ até atingirem peso constante, quando foi determinada a participação de cada componente na massa de forragem da pastagem.

O delineamento experimental foi o de blocos ao acaso com três repetições (piquetes com área entre 1,5 e 3,0 ha) por tratamento (altura do pasto). O modelo matemático utilizado na análise dos parâmetros estimados foi:

$$
\mathrm{Y}_{\mathrm{ijk}}=\mu+\mathrm{A}_{\mathrm{i}}+\mathrm{P}_{\mathrm{j}}+\mathrm{B}_{\mathrm{k}}(\mathrm{A})_{\mathrm{i}}+\mathrm{A}^{*} \mathrm{P}_{\mathrm{ij}}+\varepsilon_{\mathrm{ijk}}
$$

em que $Y_{i j k}=$ variáveis dependentes; $\mu=$ média de todas as observações; $A_{i}=$ efeito da i-ésima altura pretendida; $P_{j}=$ efeito do j-ésimo período; $\mathrm{R}_{\mathrm{k}}(\mathrm{A})_{\mathrm{i}}=$ efeito do k-ésimo bloco (unidade experimental) dentro da i-ésima altura pretendida (erro $\mathrm{A}) ; \mathrm{A}^{*} \mathrm{P}_{\mathrm{ij}}=$ efeito de interação entre a i-ésima altura pretendida e o j-ésimo período; $\varepsilon_{\mathrm{ijk}}=\operatorname{erro}$ residual (erro B).

As variáveis estudadas foram submetidas a análise de variância e ao teste F a 5\% de significância. Quando detectadas diferenças entre as alturas pretendidas, realizaram-se comparações de médias pelo teste Tukey a 5\% de significância. Análises de regressão também foram utilizadas para os dados relacionados à produção do pasto utilizando-se o seguinte modelo:

$$
\mathrm{Y}_{\mathrm{ij}}=\mu+\mathrm{b}_{1} \mathrm{~A}_{\mathrm{i}}+\mathrm{b}_{2} \mathrm{~A}^{2}{ }_{\mathrm{i}}+\operatorname{erro}\left({ }_{\mathrm{i}, \mathrm{j}}\right)
$$

em que $\mathrm{A}=$ alturas de manejo do pasto $\left({ }_{\mathrm{i}}=1,2,3,4, \mathrm{SP}\right)$; $\mathrm{b}_{1}=$ coeficientes lineares de regressão da variável Y de acordo com a altura do pasto; $b_{2}=$ coeficientes quadráticos de regressão da variável Y relacionada à altura do pasto.

As análises foram feitas pelo procedimento GLM (General Linear Models) do programa estatístico SAS, versão 6.08 (SAS, 1989).

\section{Resultados e Discussão}

Segundo o zoneamento agroclimático do Rio Grande do Sul (Moreno, 1961), a área experimental é considerada zona preferencial para o cultivo de forrageiras temperadas. Portanto, os valores de precipitação média durante o período experimental estão no regime hídrico favorável ao desenvolvimento de pastagens de aveia e azevém (Tabela 1).

A taxa de lotação média aplicada no estabelecimento e na manutenção das alturas do pasto de aveia e azevém decresceu de forma linear com o aumento da altura. De acordo com a equação de regressão ( $\mathrm{y}=2266,46$ - 41,72x; $\left.\mathrm{CV}=11,4 \% ; \mathrm{R}^{2}=0,96 ; \mathrm{P}<0,05\right)$, cada $\mathrm{cm}$ de aumento na 
altura do pasto correspondeu à redução na taxa de lotação de aproximadamente $42 \mathrm{~kg} / \mathrm{ha}$ de PV. Com adubação de cobertura de $90 \mathrm{~kg} / \mathrm{ha}$ de nitrogênio, a maior taxa de lotação média obtida foi de $1.999 \mathrm{~kg} /$ ha de PV na altura 10 $\mathrm{cm}$, superior ao valor obtido por Cassol (2003), de $1.359 \mathrm{~kg} / \mathrm{ha}$ de PV, na mesma altura de pasto mas com a metade da adubação de cobertura utilizada neste estudo ( $45 \mathrm{~kg} / \mathrm{ha}$ de N). Segundo Soares et al. (2002), aumentos significativos na taxa de lotação são obtidos com o uso de doses elevadas de nitrogênio. Assmann et al. (2004) observaram que a taxa de lotação aumentou de forma linear com doses crescentes de nitrogênio $(\mathrm{N})$ e atingiu peso vivo de $1.878 \mathrm{~kg} / \mathrm{ha} / \mathrm{dia}$ com $300 \mathrm{~kg} / \mathrm{ha}$ de nitrogênio.

A relação entre altura de manejo pretendida e a altura observada (medida no pasto) se evidenciou principalmente no último período de avaliação (Tabela 2). No início do período, a altura média do pasto foi de $25 \mathrm{~cm}$ e a massa de forragem de $2.000 \mathrm{~kg} / \mathrm{ha}$ de MS. Nas alturas 30 e $40 \mathrm{~cm}$, utilizaram-se taxas de lotação que consumissem apenas parte da taxa de acúmulo para se atingir o mais rápido possível a altura pretendida. O manejo da lotação permitiu que as alturas se aproximassem do pretendido em aproximadamente 20 dias. As intensidades de pastejo estabelecidas proporcionaram amplitude de altura do pasto considerada adequada para avaliação da dinâmica de produção de forragem, uma vez que as médias das alturas do pasto observadas no período de pastejo foram 14,0;24,1;38,7 e 46,6 cm, respectivamente, para as alturas pretendidas de $10 ; 20 ; 30$ e $40 \mathrm{~cm}$, que diferiram $(\mathrm{P}<0,01)$ entre si.

A maior altura do pasto sob pastejo $(46,6 \mathrm{~cm})$ não diferiu da altura medida sem a presença de animais, tanto na média de todo o período como dentro de cada período, ou seja, a taxa de lotação utilizada para manter a altura pretendida de $40 \mathrm{~cm}$ não afetou a altura de manejo em comparação à área sem pastejo.

Nas alturas observadas, em todas as avaliações, os valores obtidos foram superiores às alturas pretendidas, o que comprova regularidade no manejo da pastagem (Figura 1).

A massa de forragem (MF) aumentou de acordo com a altura de manejo do pasto (Tabela 3). Conforme equação de regressão, para cada $\mathrm{cm}$ de aumento na altura $(\mathrm{P}<0,05)$ acima de $10 \mathrm{~cm}$, a massa de forragem aumenta $86,3 \mathrm{~kg} / \mathrm{ha}$ de MS, valor inferior ao obtido por Cassol (2003), que observou $130 \mathrm{~kg} / \mathrm{ha}$ de MS para cada $\mathrm{cm}$ de aumento na altura do pasto de aveia e azevém. Resposta semelhante entre altura do pasto e massa de forragem foi observada por Castro (2002), de $106 \mathrm{~kg} / \mathrm{ha}$ de MS, em pastagem de milheto com ovinos manejada nas mesmas alturas.
Em estudo com azevém perene, Bircham \& Hodgson (1983) obtiveram valores de massa de forragem de $900 \mathrm{e}$ $2.000 \mathrm{~kg} / \mathrm{ha}$ de MS nas alturas de 3 e $10 \mathrm{~cm}$ de altura do dossel da pastagem. Em pastagem de capim-tifton 85, a relação foi de 10 e $20 \mathrm{~cm}$ para massa de forragem de $4.000 \mathrm{e}$ $6.000 \mathrm{~kg} / \mathrm{ha}$ de MS e, em pastagem de capim-marandu, de 20 e $40 \mathrm{~cm}$ para 5.000 e $12.000 \mathrm{~kg} / \mathrm{ha}$ de MS, respectivamente (Marcelino et al., 2006), superiores aos observados em pastagens de clima temperado.

A massa média anual mantida nas pastagens foi de $2.370 ; 3.165 ; 4.298 ; 4.767 \mathrm{~kg} /$ ha de MS, que correspondeu às alturas reais de 14;24;39 e $47 \mathrm{~cm}$, respectivamente. Segundo Hodgson (1990), a massa de forragem deve ser superior a $1.500 \mathrm{~kg} / \mathrm{ha}$ de MS para não limitar o consumo de bovinos em gramíneas hibernais. Assmann et al. (2004), em pastagem de aveia, azevém e trevo-branco com altura média de manejo de $14 \mathrm{~cm}$, obtiveram massa de forragem média de $1.200 \mathrm{~kg} / \mathrm{ha}$ de MS. Ressalta-se que o método utilizado por esses autores para controle da altura foi o disco medidor. Cassol (2003) obteve, na média de dois anos de avaliação, valores de

Tabela 2 - Altura pretendida $(\mathrm{cm})$ e altura observada $(\mathrm{cm})$ na pastagem de aveia + azevém ao longo do período experimental

\begin{tabular}{lcccc}
\hline $\begin{array}{l}\text { Altura } \\
(\mathrm{cm})\end{array}$ & \multicolumn{3}{c}{$\begin{array}{c}\text { Altura efetiva } \\
(\mathrm{cm})\end{array}$} & \multirow{3}{*}{ Média } \\
\cline { 2 - 4 } & \multicolumn{4}{c}{ Período } \\
\cline { 2 - 4 } & $21 / 7$ a $22 / 8$ & $23 / 8$ a $26 / 9$ & $27 / 9$ a $7 / 11$ \\
\hline 10 & $22,8 \mathrm{c}$ & $13,1 \mathrm{c}$ & $7,7 \mathrm{~d}$ & $14,0 \mathrm{~d}$ \\
20 & $26,7 \mathrm{bc}$ & $22,9 \mathrm{c}$ & $19,8 \mathrm{c}$ & $24,1 \mathrm{c}$ \\
30 & $34,7 \mathrm{~b}$ & $40,2 \mathrm{~b}$ & $37,1 \mathrm{~b}$ & $38,7 \mathrm{~b}$ \\
40 & $47,6 \mathrm{a}$ & $57,7 \mathrm{a}$ & $42,2 \mathrm{~b}$ & $46,6 \mathrm{a}$ \\
Sem pastejo & $48,5 \mathrm{a}$ & $67,2 \mathrm{a}$ & $51,7 \mathrm{a}$ & $52,8 \mathrm{a}$ \\
CV\% & 9,14 & 9,36 & 12,07 & 8,42
\end{tabular}

Letras distintas na mesma coluna diferem $(P<0,05)$ entre si pelo teste Tukey.

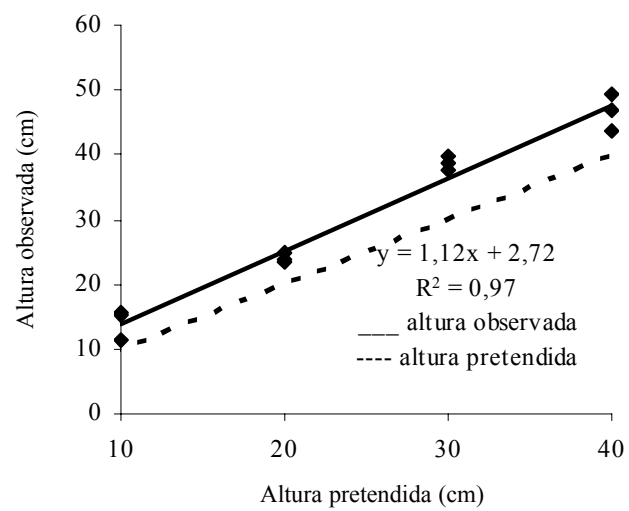

Figura 1 - Relação entre altura do pasto pretendida e observada (cm) em pastagem de aveia + azevém. 
8,6 cm de altura de pasto de aveia e azevém para massa de forragem média de $1.344 \mathrm{~kg} / \mathrm{ha}$ de MS.

A massa de forragem (Tabela 3) mostrou-se variável ao longo dos três períodos avaliados, fato comprovado pela interação altura do pasto $\times$ período de avaliação $(\mathrm{P}<0,05)$. As alturas de manejo de 39 e $47 \mathrm{~cm}$ não diferiram entre si $(\mathrm{P}>0,05)$ quanto à massa de forragem nos períodos de avaliação, portanto, provavelmente a quantidade de palhada residual não é alterada quando o pasto é manejado acima de $40 \mathrm{~cm}$.

Ao longo do período experimental, a massa de forragem diferiu entre as alturas do pasto, pois reduziu na menor altura $(10 \mathrm{e} 20 \mathrm{~cm})$ e aumentou na maior altura $(40 \mathrm{~cm}$ e sem pastejo) (Figura 2). A pastagem manejada a $30 \mathrm{~cm}$ (altura observada $=34,7 \mathrm{~cm}$ ) apresentou massa de forragem mais constante ao longo do período de pastejo, entre 4.000 e $4.400 \mathrm{~kg} / \mathrm{ha}$ de MS. Provavelmente nesta faixa de massa de forragem tenha ocorrido melhor balanço entre a redução do número de folhas vivas e o aumento do tamanho das folhas, pois perfilhos mais desenvolvidos possuem maior peso de lâmina foliar e menor porcentagem de folhas vivas (Zimmer et al., 1988). A manutenção dessa altura de dossel forrageiro resultou em uma pastagem com massa de forragem estável, o que torna mais simplificado o manejo da lotação. Provavelmente, pastagens em equilíbrio (neste caso, a $39 \mathrm{~cm}$ de altura) indicam situação de índice de área foliar (IAF) próximo ao IAF máximo, no qual o novo crescimento é igual ao que senesce, morre e é consumido (Korte et al., 1987). Portanto, manter índice de área foliar ótimo, que permita máximas taxas de crescimento da pastagem, deve ser um dos objetivos do manejo da desfolhação (Nabinger \& Pontes, 2001). Valores semelhantes de massa de forragem podem representar pastagens completamente diferentes em estrutura, pois podem variar em densidade, altura e composição para mesma massa de forragem (Carvalho et al., 2001) e resultar em diversos índices de área foliar. Nesse sentido, o manejo da lotação de acordo com a altura do pasto pode ser uma ferramenta mais adequada para manutenção de índice de área foliar médio próximo do ótimo.

Em sistema de integração lavoura-pecuária, a massa de forragem final se torna relevante na discussão. A proposta de estudar alturas de manejo está diretamente relacionada às quantidades de MS remanescente ao término do ciclo de pastejo, as quais constituem a palhada para a semeadura direta da cultura subseqüente. Neste trabalho, a massa de forragem final foi maior $(\mathrm{P}<0,05)$ na altura de $47 \mathrm{~cm}$ e na pastagem sem pastejo em comparação às alturas menores (14 e $24 \mathrm{~cm}$ ), enquanto a altura $39 \mathrm{~cm}$ se manteve na posição intermediária, considerando o valor de mínima significância de $1.708 \mathrm{~kg} / \mathrm{ha}$ de MS (Figura 2). Cassol (2003) não observou diferença nos manejos a 39 e $47 \mathrm{~cm}$, que apresentaram valores de massa de forragem final de 4.679 e $4.744 \mathrm{~kg} / \mathrm{ha} \mathrm{de}$ MS, respectivamente, indicando que pastos manejados acima de $30 \mathrm{~cm}$ não acumulam maior quantidade de MS.

Trabalhos que relacionam massa de forragem no inverno e o rendimento de grãos da cultura de verão são muito escassos na literatura brasileira. Bassani et al. (1995) e Bassani (1996), em pastagens de aveia e azevém pastejadas e não pastejadas, obtiveram massa de forragem média de 1.996 e $3.043 \mathrm{~kg} / \mathrm{ha}$ de MS, respectivamente. No verão, observaram rendimentos de grãos de milho de $5.246 \mathrm{~kg} / \mathrm{ha}$ na área pastejada e de $5.636 \mathrm{~kg} / \mathrm{ha}$ na área não pastejada, que não diferiram quanto aos rendimentos. Nicoloso et al. (2006) também observaram que intensidades de pastejo moderadas não prejudicam as produções de soja e milho cultivados na seqüência em comparação à área sem pastejo.

Considerando a segurança e sustentabilidade do sistema ao longo do tempo, baixas massas de forragem remanescentes podem comprometer o sucesso do sistema, ao passo que a manutenção de maior quantidade de palhada poderia beneficiar a cultura de verão em situação de déficit hídrico, em virtude da maior retenção de umidade e da manutenção da temperatura no solo.

Tabela 3 - Massa de forragem ( $\mathrm{kg} / \mathrm{ha}$ de MS) em pastagem de aveia + azevém manejada em diferentes alturas (cm) durante o período pastejo

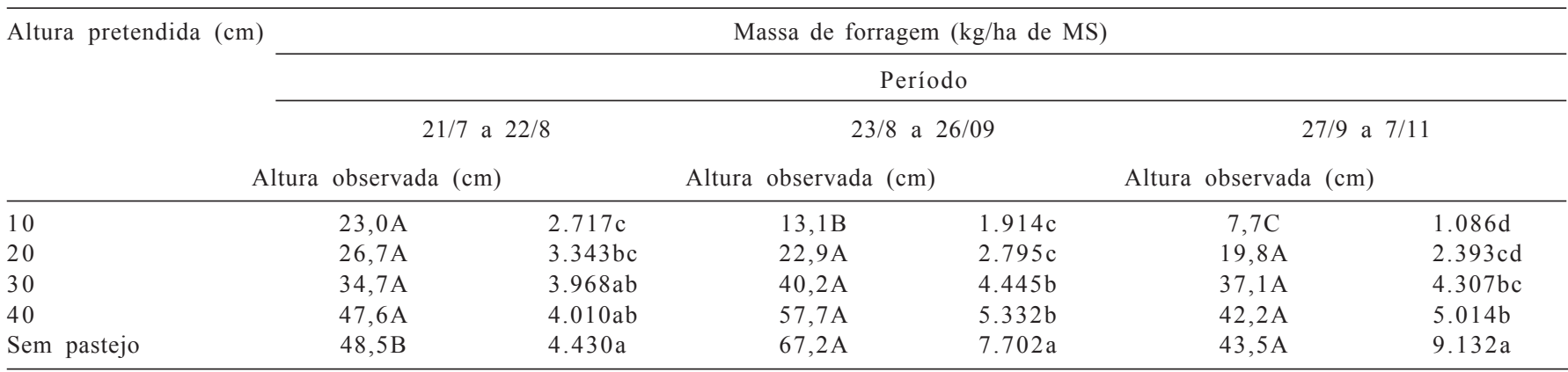

$\mathrm{CV}=11,82 \%$

Médias com letras distintas minúsculas (na coluna) e maiúsculas (na linha) diferem $(P<0,05)$ entre si pelo teste Tukey. 


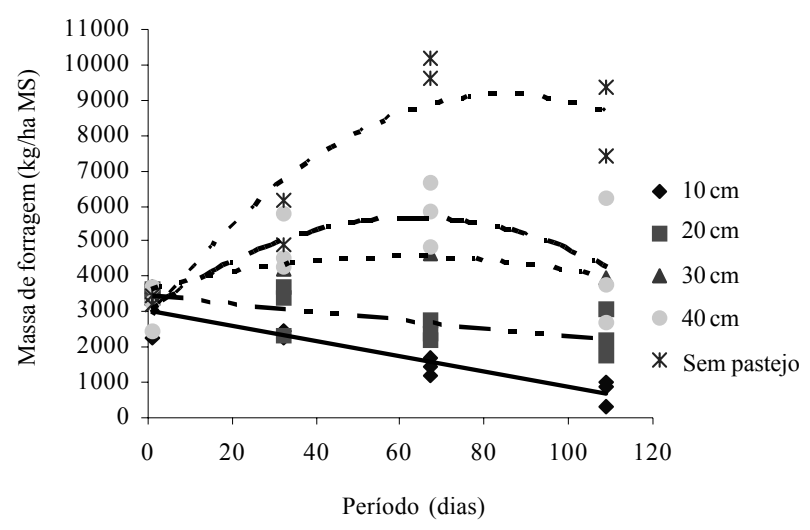

Valor de mínima significância $=1708,4 \mathrm{~kg} / \mathrm{ha}$ de MS.

Figura 2 - Massa de forragem (kg MS/ha) em pastagem de aveia + azevém manejada em diversas alturas durante o período pastejo. Médias ponderadas de acordo com a duração de cada período.

A taxa de acúmulo diário de MS (TAC), na média de todo o período, e a produção total de forragem não foram influenciadas $(\mathrm{P}>0,05)$ pelas alturas de manejo da pastagem, tampouco pela interação altura de manejo $\times$ período de avaliação (Tabela 4), o que evidencia possíveis limitações da metodologia utilizada, que poderia estar favorecendo o acúmulo de forragem nas menores alturas e subestimando nas maiores alturas, diminuindo a amplitude de eventuais diferenças entre pastos baixos e altos (Frame, 1981).

Não houve diferença na taxa diária de acúmulo de MS não diferiu entre as alturas de manejo no primeiro período $(\mathrm{P}<0,05)$ (Tabela 4). No período de $23 / 8$ a 26/9, a TAC foi maior na pastagem sem pastejo $(125,3 \mathrm{~kg} / \mathrm{ha} /$ dia de MS $)$, que apresentou, no entanto, a menor TAC, $3,5 \mathrm{~kg} / \mathrm{ha} / \mathrm{dia}$ de MS, no último período de avaliação, evidenciando redução no ciclo produtivo da pastagem excluída do pastejo. Segundo Rocha et al. (2004), pastagens de aveia e azevém, quando não pastejadas, aceleram seu ciclo de desenvolvimento, elongando os entrenós e apresentando florescimento precoce. $\mathrm{O}$ acúmulo diário mínimo e máximo durante todo o período de pastejo foi de 27,6 e 94,2 kg/ha de MS para 10 e $40 \mathrm{~cm}$ de altura, respectivamente. Lupatini et al. (1998) verificaram TAC diária de $96 \mathrm{~kg} / \mathrm{ha}$ de MS em uma mistura de aveia e azevém com dose de $300 \mathrm{~kg} /$ ha de nitrogênio. Na Depressão Central do Rio Grande do Sul, foram verificadas em pastagem de aveia e azevém taxas de acúmulo diário de forragem médias de 40 e $50 \mathrm{~kg} / \mathrm{ha}$ de MS em experimentos com novilhas de corte em pastejo contínuo (Soares, 1999; Roso etal., 2000; Frizzo, 2001; Freitas etal., 2002; Rocha etal., 2003).

A presença de folhas de aveia e azevém é determinada pelo período de utilização da pastagem, uma vez que o componente folha de azevém predomina nos três períodos de pastejo (Figura 3).

No período inicial de utilização da pastagem, há dominância de aveia (colmo + lâmina), em decorrência de sua precocidade, arquitetura e disposição de folhas, que promovem maior participação nas camadas mais altas da estrutura do pasto, principalmente em maior altura de manejo. A participação de azevém aumentou ao longo do período de pastejo, porém, no final do ciclo da pastagem, esta contribuição foi sobretudo de colmos. Quando utilizado em misturas, o azevém apresenta desenvolvimento lento no início do ciclo e aumenta sua produção em temperaturas mais elevadas na primavera (Floss, 1989). Assmann et al. (2004) observaram valores de 73,1 e 24,6\% para aveia e azevém, respectivamente, na composição botânica inicial da pastagem. No período final de avaliação, a porcentagem de azevém passou a $82,4 \%$ enquanto a aveia contribuiu apenas com $12 \%$ da massa seca da pastagem.

A estrutura da pastagem sofreu acentuada modificação conforme o estádio fenológico das espécies e conforme a altura de manejo do pasto. Durante o ciclo vegetativo, verificou-se maior proporção de folhas em relação ao período final (florescimento). A porcentagem de folha de azevém na menor altura de pastejo não reduziu sua participação ao longo do período de avaliação e foi superior à obtida nas demais alturas na última avaliação (em torno de $20 \%$ da biomassa aérea total $)(\mathrm{P}<0,05)$. Para melhorar o desempenho animal em pastagem plantada de inverno, deve-se dar especial atenção à contribuição de lâminas foliares na massa de forragem da pastagem, uma vez que sua participação depende principalmente do estádio de desenvolvimento da aveia e do azevém.

Bittencourt \& Veiga (2001) obtiveram proporção de lâminas foliares no pasto de capim-marandu de 22,9 a $29,6 \%$ em massa de forragem de 2.000 e $4.500 \mathrm{~kg} / \mathrm{ha}$ de MS. Segundo Carnevalli et al. (2001 ab), os pastos compostos dos capins tifton 85 e coastcross apresentaram 15,4 e $19,4 \%$ de lâminas foliares na massa de forragem. Nunes et al. (1995), com intervalo de cortes de 90 dias em capimmarandu, verificaram proporção de lâminas foliares média de $33,5 \%$, provavelmente porque os dados foram obtidos em pastos compostos por espécies $\mathrm{C} 4$, que possuem maior proporção de componentes de parede celular e cujo crescimento é muito acelerado (Corsi \& Nascimento Jr., 1994). Além disso, o pastejo sob lotação contínua permite aos animais selecionar mais folhas, as quais são constantemente removidas do dossel, o que pode também afetar a proporção desse componente na massa de forragem. 
Tabela 4 - Taxas de acúmulo de MS (kg/ha de MS/dia) de pastagem de aveia + azevém manejadas em diversas alturas durante o período experimental

\begin{tabular}{|c|c|c|c|c|c|c|c|}
\hline \multirow[t]{4}{*}{ Altura pretendida $(\mathrm{cm})$} & \multicolumn{6}{|c|}{ Taxa de acúmulo diário ( $\mathrm{kg} / \mathrm{ha}$ de $\mathrm{MS}$ ) } & \multirow[t]{4}{*}{ Média } \\
\hline & \multicolumn{6}{|c|}{ Período } & \\
\hline & \multicolumn{2}{|c|}{$21 / 7$ a $22 / 8$} & \multicolumn{2}{|c|}{$23 / 8$ a $26 / 9$} & \multicolumn{2}{|c|}{$27 / 9$ a $07 / 11$} & \\
\hline & \multicolumn{2}{|c|}{ Altura real $(\mathrm{cm})$} & \multicolumn{2}{|c|}{ Altura real $(\mathrm{cm})$} & \multicolumn{2}{|c|}{ Altura real $(\mathrm{cm})$} & \\
\hline 10 & 23,0 & $74,1 \mathrm{a}$ & 13,1 & $73,4 \mathrm{~b}$ & 7,7 & $27,6 \mathrm{a}$ & $56,0 \mathrm{a}$ \\
\hline 20 & 26,7 & $67,8 \mathrm{a}$ & 22,9 & $63,4 b$ & 19,8 & $53,4 \mathrm{a}$ & $60,8 \mathrm{a}$ \\
\hline Sem pastejo & 48,5 & $67,4 \mathrm{a}$ & 67,2 & $125,3 \mathrm{a}$ & 43,5 & $3,5 b$ & $61,4 \mathrm{a}$ \\
\hline *Média & 68,79 & 89,14 & 44,64 & 65,68 & & & \\
\hline $\mathrm{CV} \%$ & 36,03 & 19,46 & 20,76 & 36,86 & & & \\
\hline
\end{tabular}

a,b na mesma coluna diferem entre si $(P<0,05)$.

${ }^{*} y=4,476+2,691 P-0,021 P^{2} R^{2}=0,310 P<0,01$.
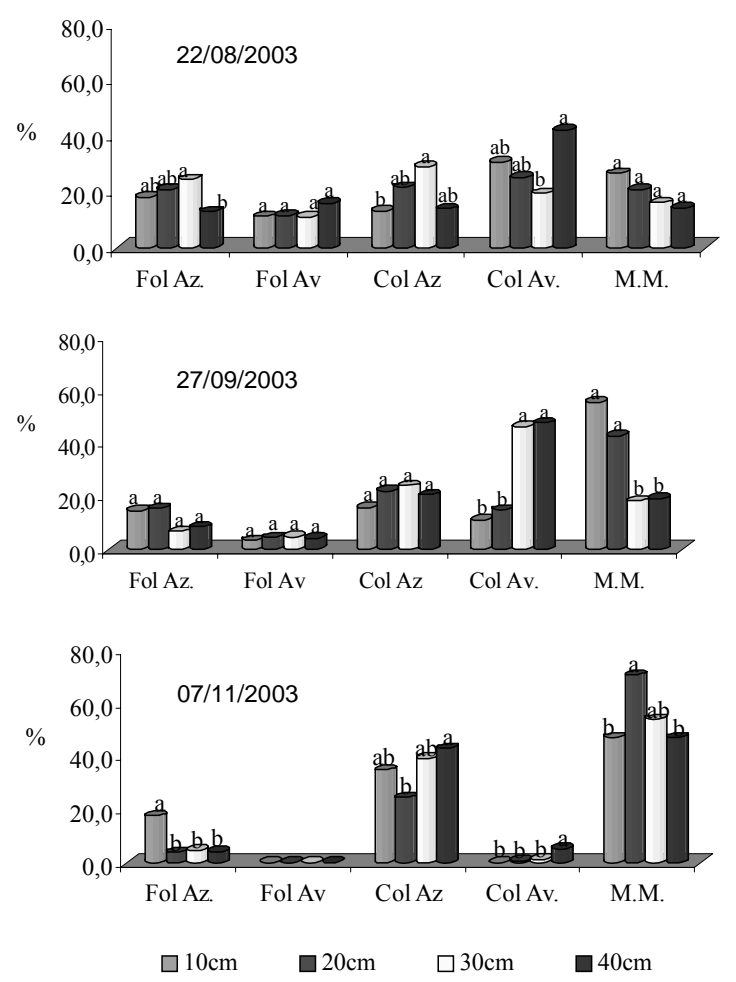

Figura 3 - Proporção de folhas de azevém (Fol Az.) e de aveia (Fol. Av), colmo de azevém (Col Az) e de aveia (Col Av) e material morto (MM) da pastagem de aveia + azevém manejada em diversas alturas durante o período experimental.

Com o aumento do período de utilização do pasto, houve aumento do componente material morto, que diferiu entre as alturas da pastagem de aveia e azevém. As pastagens de 10 e $20 \mathrm{~cm}$ de altura de pastejo apresentaram os maiores valores de MS nas duas primeiras avaliações. $\mathrm{Na}$ avaliação do dia 7/11, a pastagem manejada a $20 \mathrm{~cm}$ apresentou o maior valor de MM , 70\%. Em anos anteriores, Cassol et al. (2003) constataram na mesma área valores em torno de $77 \mathrm{e} 74 \%$ para as alturas de $10 \mathrm{e} 20 \mathrm{~cm}$ aos 79 dias de pastejo. Valores inferiores aos deste estudo foram obtidos por Roso (1999) em pastagens de triticale ou aveiapreta ou triticale e aveia-preta + azevém com massa de forragem semelhante a $1.670 \mathrm{~kg} /$ ha de MS, que apresentam no final do ciclo, valores de 23,9; 36,4; 29,8\% de MM, em virtude da senescência das plantas de triticale e aveia, que se encontravam próximas da fase reprodutiva.

\section{Conclusões}

A massa de forragem de pastagens de aveia + azevém submetidas a pastejo com lotação contínua aumenta linearmente de acordo com a altura de manejo, propiciando maiores resíduos para a lavoura de grãos subseqüentes. As taxas de acúmulo não foram influenciadas pelas alturas estudadas. Pastos de aveia e azevém manejados entre 25 e $35 \mathrm{~cm}$ de altura apresentam massa de forragem relativamente constante ao longo do período de utilização, em torno de $3.000 \mathrm{~kg} / \mathrm{ha}$ de MS, o que indica equilíbrio dinâmico entre produção, morte e consumo de tecidos.

\section{Agradecimento}

Ao Grupo de Pesquisa em Ecologia do Pastejo da UFRGS; aos Departamentos de Plantas Forrageiras e Agrometeorologia e de Solos da Faculdade de Agronomia/ UFRGS; à Agropecuária Cerro Coroado; à CAPES; e ao CNPq.

\section{Literatura Citada}

ASSMANN, A.L.; PELISSARI, A.; MORAES, A. et al. Produção de gado de corte e acúmulo de matéria seca em sistema de integração lavoura-pecuária em presença ou ausência de trevo branco e Nitrogênio. Revista Brasileira de Zootecnia, v.33, n.1, p.3744,2004

ASSOCIATION OF OFFICIAL ANALYTICAL CHEMISTS AOAC. Official methods of analysis. 14.ed. Washington, D.C.: $1984.1141 \mathrm{p}$. 
BARTHRAM, G.T. Experimental techniques: the HFRO sward stick. Midlothian: Hill Farming Research Organization/Biennial Report. 1985. p.29-30.

BASSANI, H.J. Propriedades físicas induzidas pelo plantio direto e convencional em área pastejada e não pastejada. Santa Maria: Universidade Federal de Santa Maria, 1996. 90p. Dissertação (Mestrado em Agronomia) - Universidade Federal de Santa Maria, 1996

BASSANI, H.J.; REINERT, D.J.; SCAPINI, C.A. et al. Efeito do plantio direto e convencional em áreas com pisoteio animal sobre algumas propriedades físicas do solo e produtividade de milho. In: CONGRESSO BRASILEIRO DE CIÊNCIA DO SOLO, 25., 1995, Viçosa, MG. Anais... Viçosa, MG: Sociedade Brasileira de Ciência do Solo, 1995. p.1819-1821.

BIRCHAN, J.S.; HODGSON, J. The influence of swards conditions on rate of herbage growth and senescence in mixed swards under continuous grazing management. Grass and Forage Science, v.38, p.323-331, 1983

BITTENCOURT, P.C.S.; VEIGA, J.B. Avaliação de pastagens de Brachiaria brizantha cv. Marandu em propriedades leiteiras de Ururá, região da Transamazônica, Pará, Brasil. Pastures Tropicales, v.23, n.2, p.2-9, 2001

CARNEVALLI, R.A.; DA SILVA, S.C.; CARVALHO, C.A.B. et al. Desempenho de ovinos e respostas de pastagens de coastcross submetidas a regimes de desfolha sob lotação contínua. Pesquisa Agropecuária Brasileira, v.36, n.6, p.919-927, 2001a.

CARNEVALLI, R.A.; DA SILVA, S.C.; FAGUNDES, F.L. et al. Desempenho de ovinos e respostas de pastagens de Tifton 85 (Cynodon spp.) sob lotação contínua. Scientia Agrícola, v.58, n.1, p. 7-15, $2001 \mathrm{~b}$.

CARVALHO, P.C.F.; RIBEIRO FILHO, H.M.N.; POLI, C.H.E.C. et al. Importância da estrutura da pastagem na ingestão e seleção de dietas de animais pelo animal em pastejo. In: MATTOS, W.R.S. et al. (Ed.) Produção animal na visão dos brasileiro. Piracicaba: Fundação de Estudos Agrários Luiz de Queiroz, 2001. p.853-871.

CASSOL, L.C. Relações solo-planta-animal num sistema de integração lavoura-pecuária em semeadura direta com calcário na superfície. Porto Alegre: Universidade Federal do Rio Grande do Sul, 2003. 143p. Tese (Doutorado em Agronomia - Ciência do solo) - Universidade Federal do Rio Grande do Sul, 2003.

CASTRO, C.R.C. Relações planta-animal em pastagem de milheto (Pennisetum americanum (L) Leeke.) manejada em diferentes alturas com ovinos. Porto Alegre: Universidade Federal do Rio Grande do Sul, 2002. 185p. Dissertação (Mestrado em Zootecnia) - Universidade Federal do Rio Grande do Sul, 2002 .

CORSI, M.; NASCIMENTO JR., D. Princípios de fisiologia e morfologia de plantas forrageiras aplicados no manejo das pastagens. In: PEIXOTO, A.M.; MOURA, J.C.; FARIA, V.P. (Eds.). Pastagens: fundamentos de exploração racional. 2.ed. Piracicaba: Fundação de Estudos Agrários Luiz de Queiroz, 1994. p. $15-48$

EMPRESA BRASILEIRA DE PESQUISA E AGROPECUÁRIA EMBRAPA. Centro Nacional de Pesquisa de Solos. Sistema brasileiro de classificação de solos. Brasília: EMBRAPA. Rio de Janeiro, 1999. 412p

EUCLIDES, V.P.B.; MACEDO, M.C.M.; OLIVEIRA, M.P. Avaliação de diferentes métodos de amostragem sob pastejo. Revista Brasileira de Zootecnia, v.21, n.4, p.691-702, 1992.

FLOSS, E.L. Aveia. In: BAIER, A.C.; AUDE, M.I.S.; FLOSS, E.L. (Eds.) As lavouras de inverno-1. São Paulo: Globo, 1989. p.17-74.

FRAME, J. Herbage mass. In: HODGSON, J.; LEAVER, J.D. (Eds.). Sward measurement handbook. Hurley: British Grassland Society, 1981. p.39-67.

FREITAS, F.K.; ROCHA, M.G.; BRONDANI, I.L. et al. Suplementação energética na recria de fêmeas de corte em pastagem cultivada de inverno. Dinâmica da pastagem. Revista Brasileira de Zootecnia, v.34, n.6, p.2029-2038, 2005.
FRIZZO, A.; ROCHA, M.G.; RESTLE, J. et al. Suplementação energética na recria de bezerras de corte mantidas em pastagem de inverno. Revista Brasileira de Zootecnia, v.32, n.3, p.643652,2003

HODGSON, J. Grazing management: science into pratice London: Longman Scientific \& Techinical, 1990. 203p.

KORTE, C.J.; CHU, A.C.P.; FIELD, T.R.O. Pasture production. In: NICOL, A.M. (Ed.) Feeding livestock on pasture. Hamilton: Society of Animal Production, 1987. p.7-20. (Occasional Publication, 10).

LUPATINI, G.C.; RESTLE. J.; CERETTA, M. et al. Avaliação da mistura de aveia preta (Avena strigosa) e azevém (Lolium multiflorum) sob pastejo submetida a níveis de nitrogênio. Pesquisa Agropecuária Brasileira, v.33, n.11, p.1939-1943 1998.

MACHADO, M.L.S.; RADOMSKI, M.I.; VIEIRA, J.A.N. et al. A integração lavoura-pecuária na agricultura familiar no sudoeste do Paraná. In: ENCONTRO DE INTEGRAÇÃO LAVOURAPECUÁRIA NO SUL DO BRASIL, 1., 2002, Pato Branco. Palestras... Pato Branco: 2002. p.109-130.

MARCELINO, K.R.A.; NASCIMENTO JR., D.; DA SILVA, S.C. et al. Características morfogênicas e estruturais e produção de forragem do capim-marandu submetido a intensidades e freqüências de desfolhação. Revista Brasileira de Zootecnia v.35, n.6, p.2243-2252, 2006.

MOREnO, J.A. Clima do Rio Grande do Sul. Porto Alegre: Secretaria da Agricultura, 1961. 41p.

MOTT, G.O.; LUCAS H.L. The design, conduct, and interpretation of grazing trials on cultivated and improved pastures. In INTERNATIONAL GRASSLAND CONGRESS, 6., 1952 , Pensylvania. Proceedings... Pensylvania: 1952. p.1380-1385.

NABINGER, C.; PONTES, L.S. Morfogênese de plantas forrageiras e estrutura do pasto. In: MATTOS, W.R.S. et al. (Eds.) Produção animal na visão dos brasileiro. Piracicaba: Fundação de Estudos Agrários Luiz de Queiroz, 2001. p.751-755.

NICOLOSO, R.S.; LANZANOVA, M.E.; LOVATO, T. Manejo das pastagens de inverno e potencial produtivo de sistemas de integração lavoura-pecuária no Estado do Rio Grande do Sul. Ciência Rural, v.36, n.6, p.1799-1805, 2006.

NUNES, S.G.; BOOCK, A.; PENTEADO, M.I.O. Brachiaria brizantha cv. Marandu. 2.ed. Campo Grande: EMBRAPA CNPGC, 1985. 31p. (Documentos, 21.)

RESTLE, J.; ROSO, C.; SOARES, A.B. et al. Produtividade animal e retorno econômico em pastagem de aveia preta mais azevém adubada com fontes de nitrogênio em cobertura. Revista Brasileira de Zootecnia, v.29, n.2, p.357-364, 2000

ROCHA, G.M.; MONTAGNER, D.B.; SANTOS, D.T. et al Parâmetros produtivos de uma pastagem temperada submetida a alternativas de utilização. Revista Brasileira de Zootecnia v.33, n.6, p.1386-1395, 2004

ROCHA, M.G.; RESTLE, J.; FRIZZO, A. et al. Alternativas de utilização da pastagem hibernal para a recria de bezerras de corte. Revista Brasileira de Zootecnia, v.32, n.2, p.383-392, 2003.

ROSO, C.; RESTLE, J.; SOARES, A.B. et al. Produção e qualidade de forragem da mistura de gramíneas anuais de estação fria sob pastejo contínuo. Revista Brasileira de Zootecnia, v. 28 n.3, p.459-467, 1999.

ROSO, C.; RESTLE, J. Aveia preta, triticale e centeio em mistura com azevém. 2. Produtividade animal e retorno econômico. Revista Brasileira de Zootecnia, v.29, n.1, p.85-93, 2000

STATISTICAL ANALYSIS SYSTEM - SAS. SAS/STAT: user's guide: statistics. 4.ed. Version 6, Cary: SAS Institute, 1989. v.2, 943p.

SOARES, A.B.; RESTLE, J. Produção animal e qualidade de forragem de pastagem de triticale e azevém submetida a doses de adubação nitrogenada. Revista Brasileira de Zootecnia, v.31, n.2, p.908-917, 2002 (supl.)

ZIMMER, A.H.; EUCLIDES, V.P.B.; FILHO, K.E. et al. Considerações sobre indices de produtividade da pecuária de corte em Mato Grosso do Sul. Campo Grande: EMBRAPA CNPGC, 1998. 53p. (Documentos, 70). 